\title{
The Contribution of International Business to the Economic Development of Yunnan Province
}

\author{
Dr John Walsh (corresponding author) \\ School of Management, Shinawatra International University \\ BBD Building (Viphawadi), 197, Viphawadi-Rangsit Road \\ Phaya Thai, Bangkok 10400, Thailand \\ Tel: 66-2-650-6031. Fax: 66-2-650-6033 E-mail: jcwalsh@siu.ac.th \\ Sittichai Anantarangsi \\ School of Management, Shinawatra International University
}

\begin{abstract}
Yunnan province is the closest part of China to mainland Southeast Asia and represents an important commercial link between the two separate markets. Its capital, Kunming, is becoming linked to Bangkok and other cities through the provision of transportation infrastructure and trade is increasing. However, it is not clear whether the business conditions within Yunnan are yet appropriate for the kind of trade and investment that international businesspeople wish to transact there. Using a program of qualitative research featuring in-depth personal interviews, the authors investigate the actual business conditions in Kunming principally but also in the remainder of the province. They find that much economic development is taking place as a result of large-scale state activity that is able to take advantage of economies of scope and scale. Meanwhile, much international business is hampered by the weak nature of institutions supporting the business infrastructure and the nature of a number of informal and unofficial barriers to entry and development.
\end{abstract}

Keywords: Economic development, Private sector, Yunnan province, Government

\section{Introduction}

Yunnan Province is the closest part of China to mainland Southeast Asia and is generally included as part of the Greater Mekong Sub-Region (GMSR). Its historical, cultural and geographical nature link it strongly with the other countries of the GMSR, which are Vietnam, Burma (Myanmar), Laos, Vietnam, Cambodia and Thailand. As part of a China transitioning from command economy mechanisms to a market-based economic system, Yunnan Province has enjoyed the Open Door Policy first enacted at the state level in 1978. In the first stage of the program, which took place between 1978-84, there was rapid agricultural reform, the rapid and balanced development among the three types of industry (light, medium and heavy) and the release of economic potential previously constrained by institutional factors and this resulted in a period of stable economic growth. The second stage took place between 1985-91 and witnessed drastic fluctuations in the rate of economic growth. A dramatic change in the structure of consumption led to rising income levels but high inflation. A mismatch between supply and demand resulted in chaos in production as the needed things were not made and unneeded things made instead. The third stage took place between 1992-2000 and saw stable economic growth and the firm desire to establish a socialist market state. Enterprises and residents gradually adapted to market mechanisms, while the government attempted to influence the economy more skillfully through market approaches (Gan and Chen, 2004).

Gaining experience and knowledge by government in undertaking this enormous task is vital but difficult to manage effectively - after all, knowledge management as a sub-discipline of organisational studies is still a young science. Conducting research in Vietnam in the late 1990s, the authors found that many international firms retained one or more lawyers on a more or less full-time basis whose tasks were to report to various relevant ministries on a daily basis to collect the new rulings and administrative orders issued that day and then work through the evening hours trying to determine the implications for the firm's activities. That level of change has declined now as most of the major systems have been put in place and as a result of institutional learning. However, there is still a long way to go. In China, continuing constraints to private sector development have been identified as including market competition, finance, taxation, internal governance, labour and managerial skills, technology, laws and government regulations and social infrastructure (Garnaut and Song, 2004). Many of these issues are dependent to at least some extent on the nature of any political change within China. For example, the provision of labour rights is still very limited and restricted. However, international agreements into which China has entered are likely to see pressure for these to be improved. Whether the Chinese Communist Party (CCP) is yet ready to cede some authority to such international 
agreements remains to be seen but, for the sake of the lamentable safety records in China's mines if for no other reason, it is much to be hoped.

The general policy of the CCP in the $\mathrm{C} 21^{\text {st }}$ has been to continue with a monolithic political system combined with a mixed form of economic development, which would combine private sector organizations together with the organs of the state. This poses a particular question: is this a feasible means of managing economic development? In other words, it may be an effective means of promoting aggregate development but it may not necessarily be an efficient one, in which scarce resources are used in as close to the optimal method as is practical. This issue, therefore, forms the principal research problem or problem statement: what has been the role of the private sector in shaping the economic development of Yunnan province as a whole? Once this assessment can be made, then it will be possible to comment on the effectiveness of the CCP's overall strategy for the economic development of the province. It may be noted here that most social and cultural issues are not considered in this paper.

\section{The Empirical Research}

This research project was prompted by the desire to learn to what extent the rhetoric of economic and commercial development provided by the Chinese state was matched in reality by local practitioners. Have local markets developed to meet capitalist requirements and is there a business infrastructure (of research, consultancy, legal services and design) available to support international investors? What practical difficulties do inward investors face in first entering the market and then developing their business? To answer these questions, a program of qualitative research was undertaken which was based on in-depth qualitative interviewing combined with ethnographic observation. More than 30 dedicated interviews were conducted, variously in Chinese or Thai language, during which extensive note-taking was used for subsequent transcription, interpretation into English and then analysis through content analysis techniques. Respondents were selected by convenience and snowball methods and, to counteract the problems of homogeneity of sample that this approach entails, the principle of maximum variation was further introduced into interviewee selection (List, 2004). The authors have found this approach to be a successful one in understanding complex social and economic situations in a variety of contexts (e.g. Southiseng et al., 2008; Southiseng and Walsh, 2008; Anantarangsi and Walsh, 2008). Respondents included local and foreign business investors, government officers, academics and other informed experts.

Within interviews, a semi-structured research agenda was prepared so that respondents would be invited to address the same issues but the nature of the interview was constructed to be in the form of a conversation so that respondents could digress to explore more fully the particular circumstances and issues which they faced. Experience has shown that the range of different circumstances can be quite substantial and it would be inappropriate to expect every respondent to be willing and able to address every issue that could be raised.

Overall, then, the research was qualitative in nature, featuring in depth interviews with a variety of relevant individuals. The resultant interview transcripts were combined with existing secondary data through a process of conceptual content analysis. Ethnographic observations made by the researchers have been added to the research material when the insights have been adjudged to add value to the overall understanding and to be sufficiently robust in the nature of their formation.

The research propositions that were employed to guide the research were as follows:

- the organization of public and private sector agencies and resources will have an impact on the nature and scope of overall economic development in Yunnan province;

- it is possible to understand and hence maximise overall economic development within a defined spatial location through administration of the mixture and interaction of and between public and private sector agencies.

It is assumed, for the purposes of this paper, that increasing aggregate economic development is a desirable outcome and that, effectively, the scope of total economic growth is limitless. It is acknowledged that these assumptions may be questioned.

\section{Modern Industry in Yunnan Province}

As described in the previous section, Yunnanese industry was run along standard state-controlled lines prior to the last few decades. Since state agencies determined production schedules, managers had little experience or understanding of responding to market opportunities or shaping production accordingly. Consequently, the emergence of entrepreneurial activity has been quite slow, although there have been some notable exceptions. Of course, petty entrepreneurialism continued during the command period on an illicit basis and those who managed to pursue it have the necessary skills, although they have been limited by the lack of access to capital and to key network or Guanxi relationships.

One example of a successful post-Open Door policy industrial sector to have flourished in Yunnan is the cut flower industrial sector, especially in its manifestation as an export industry. Natural comparative advantages make Yunnan 
a suitable place to grow many types of valuable plants but it was scarcely possible to market these successfully under the austerity of Maoist China. The farmers of Yunnan formed a co-operative in 1994 and soon set about growing so many products that the country's previous leading centre of production in Shanghai was outstripped (Clements-Hunt, 2004). This brought the burgeoning industry to the attention of authorities and permission was given for the state-owned tobacco industry to invest more than US\$1 million into it. This is an example of state-owned and former state-owned industries reacting to business opportunities in a pro-active and entrepreneurial manner. Subsequently, partnerships have been established with specialist groups in Amsterdam, a powerful centre for European cut flower growth and distribution, which have helped Yunnanese growers overcome problems with lack of technical capacity, marketing know-how and supply chain and quality issues. A similar case exists with respect to song rong or Matsutake mushrooms, which are grown in north-west Yunnan and now exported to Japan in large amounts (Arora, 2008).

Cut flowers are not the only products which are domestically produced and suitable for international export. Yunnan Machinery Import and Export Co. Ltd. was the first joint-stock company to be created which had previously been a state-owned enterprise. Partnerships have been created so as to utilize Chinese domestic manufacturing capacity in conjunction with global networks of demand and sourcing (Yunnan Government, 2006).

Tourism has been identified as one of the leading areas for economic development within the GMSR. It has been taking place in certain parts of Yunnan with some rapidity. Cities such as Lijiang have been, if not quite completely reinvented, then at least rapidly rebuilt to a significant extent. Unfortunately but to some extent perhaps inevitably, some of that development has resulted in the opening of karaoke bars and the increase in drugs use and similar activities. The cultural heritage of Lijiang, Jinghong and other cities now exists in a quite different form than it did in the past. At Man-chun-man village in the Xishuangbanna, tourism has followed a multi-stage development process (Hui et al., 2001). At first, a small number of domestic tourists arrived and they caused the creation of a few additional services catering for their needs, such as noodle and grilled foods stands. This had little impact on the village as a whole but some, including the head man, identified economic opportunities in expanding the scope of the activities. Traditional cultural production was emphasized to produce souvenirs for sale to tourists and houses were opened to view to show existing cultural institutions. More and more villagers became involved in these activities and the basic output of the village changed significantly. The third phase occurred when villagers redesigned and redeveloped the entire village itself, creating transportation infrastructure to channel tourism vehicles and charging entry to the village itself. The success of this process inspired competition from neighbouring villages and led to a reduction in the number of visitors. The fourth stage of tourism development began when large, non-local corporations began to build construction projects using land to unite several villages together and which occupy “... large tracts of land with large theme squares devoted to displaying ethnic customs, shopping malls, and restaurants and sites for song and dance performances (ibid.)." In this case, control over the traditional activities has been lost at the individual level and transferred to the corporate level. Villagers no longer define what is traditional and what is related to their particular culture. Instead, corporations decide on what is culturally important based upon the ability to make money from it.

It is noticeable when visiting the capital city of Kunming that there are comparatively few international visitors, although an internal market for Chinese visitors from other provinces has developed. Scholars in Kunming itself felt that the visa arrangements might contribute to the relative paucity of international tourists. This was because of both the costs and the time required to obtain a visa. Since there is still no provision for obtaining a visa on arrival, tourists must apply at a local Embassy some time in advance and this makes it less likely that international tourists in nearby countries, for example Thailand, will decide to visit on a whim. Secondly, the price for neighbouring countries (which ranges up to approximately US $\$ 150$ for American visitors and US $\$ 30$ for Lao or Burmese visitors) can also be off-putting. Most other countries in East Asia have simplified their visa requirements (partly through multilateral arrangements in ASEAN and similar) and their tourism industries have benefited as a result. Further development of the tourism industry will also be required in terms of foreign language ability and service orientation. Compared to neighbouring countries, for example, few people in Yunnan can speak English and there is very little in the way of the kind of politeness, smiling countenances and generally international level of the service mind that tourists tend to demand. Most progress has been made in this respect in Lijiang. As experience of international tourism spreads, as well as the profits that a competitive advantage in this area provides, it is anticipated that such skills and competencies will also improve. It should also be borne in mind that gender discrimination still exists in Yunnan to a considerable extent and this leads to many distortions in the labour market. Together with educational preferences, this means that the supply of people willing and able to work effectively in the service sector is still constrained. 
Nevertheless, those areas in which competitive advantage may be found through technical expertise supported by state funds, for example, in mining, have enabled some Yunnanese organizations to become internationalized and to achieve further growth through economies of scale and scope (e.g. Metal Bulletin, 2009).

\section{Border Trade}

Border trade has been an important part of Yunnan's economic profile for many centuries. Traders from Laos, Myanmar and Vietnam are among those who travel often long-distances to acquire goods form Chinese wholesale markets and distribute them throughout the region, as indeed Chinese traders do in the reverse direction. With the creation of a better road system and the signing of, in particular, the Sino-Thai Free Trade Agreement, there is now a considerable amount of road traffic bringing Chinese fruit and vegetables as well as other goods to the retail multiples of the Kingdom. Small border towns such as Ruili, Wanding and Mangshi have become quite prosperous trading centres in their own right. Roads have been upgraded to asphalt covering and numerous skilled people have moved to the area to take advantage of emergent opportunities (Gan and Chen, 2004). In 1992, the open policy that had benefited the coastal cities was extended to Kunming and Hekou, Ruili and Wanding received changes in status. This has contributed to the continued growth of Chinese influence in Mandalay and northern Myanmar generally (Fullbrook, 2006), while the Thai government has facilitated the creation of an extensive industrial estate in Chiang Rai province. The prospective opening of a third cross-Mekong bridge in that region has led to plans to extend the industrial estates to Chiang Khong and work with the Ministry of Labour in Thailand is taking place to deal with potential demand for workers and skills training (Suksamran, 2007). The investment is two-way, of course, with many examples of joint venture projects initiated by Thai firms, especially. Those firms which were created by Sino-Thai families and which have some understanding of the Chinese market and of ways of being successful there are particularly well represented in this case.

Notwithstanding the border trade that currently exists between Thailand and Yunnan, there is clearly scope for increases in the overall level. However, structural issues related to infrastructure are currently limiting the increase in trade. This includes the nature of the border port at Chiang San in Chian Rai province in the north of Thailand, which is the site of several bottlenecks, including lack of capacity in administering customs consignments and the capacity of the river to handle larger boats. The capacity issue is being tackled through blasting of rapids and building of dams along the upper part of the Mekong, although this poses obvious concerns for the environment. In any case, the seasonal flow of the river means that transportation can only take place for part of the year and many boats are limited to a stretch of the water from Jinghong downwards. At Jinghong, goods are moved to trucks for further transportation to Kunming. This issue is problematic because Thai businesspeople exporting dry goods and canned fruit to China report that up to $30 \%$ of the stock can be damaged during the journey. The alternative is to ship through Chiangtung in Burma, which is much more expensive because of various official and unofficial tariffs but has a damage rate of only $2 \%$.

Kunming is recognized as a strategically-placed location for accessing many important markets within China. Improved road links have brought coastal areas such as Guangzhou within 20 hours of travel time, Xiamen 25 hours, Shanghai 30 hours and Beijing within 34 hours. Manufacturing and market centres in the centre of the country are also comparatively convenient to reach, with Chengdu 14 hours away and Xian 22 hours. These distances are considered to be very manageable in modern China and much better than had previously obtained. The link between Kunming and Bangkok makes this connection an important one for China-GMSR trade and investment. This is so despite some attempts by the Thai government to promote the central city of Phitsanulok as the node linking the north-south highway with the yet to be completed East-West Economic Corridor. However, Bangkok remains the real centre because of its importance as a market in its own right, as well as its seaport and airports, industrial estates, the financial centre and the other parts of the business infrastructure. In any case, as some respondents pointed out, there is a danger that Kunming and the whole of Yunnan will be bypassed as a market for goods from the GMSR and will simply function as a truck stop on the way to more lucrative markets. In this case, the extent to which positive economic development will take place is problematic.

Information from a series of qualitative interviews with business executives and government officials in Kunming indicated that the completion of the R3A road linking it with Bangkok and, ultimately, Singapore represents an important opportunity for increasing trade between the two countries. However, there are some issues to be overcome. For example, Thailand uses vehicles driven from the right-hand side while in China it is the other way around. Further, Thai vehicles, as well as Lao and Vietnamese, are limited to Yunnan province, while Chinese vehicles are permitted in every part of the GMSR countries. There is also the customs issue, which is that moving from Thailand-Laos-China and back again involves many customs transactions which act to increase costs and reduce profits. Businesspeople would like there to be a single customs point, whether it is located in any of the three countries involved. However, Lao authorities point out the vital role that Lao territory plays in this trade, even though there are very few individuals or organizations in the country who participate or contribute to it. A unified 
customs point would, therefore, penalize Laos without providing compensation. Consequently, both the Thai and Chinese governments are attempting to organize human development, irrigation, environmental protection and similar projects in Laos in order to bring the government on side.

\section{Yunnan as the Site of Chinese-ASEAN Integration}

As the spatial connection between China and ASEAN, Yunnan has a large role to play in facilitating the relationship. The long historical relationship, outlined in previous sections, demonstrates the degree to which Yunnan and the Yunnanese people are integrated into a single region, at least in part. It is not just history and ethnic and trading connections which link the region as single but, also, geography. Rivers such as the Mekong and the Irrawaddy (Ayerwaddy) descend from the Tibetan highlands and pass through mainland Southeast Asia before emptying into the southern seas. Rivers provided not just convenient means of transportation in the past but virtually the only means, since the thickly forested and mountainous terrain which covered so much of the northern part of the region was so difficult to traverse. The valleys created by the river provided the most desirable land where the migrating Tais could plant their rice fields, displacing indigenous inhabitants and pushing them upslope. Some 50 million people rely in some form or other on the River Mekong in its downstream reaches. Unfortunately, the rivers have become a source of division as much as unity as China has set about a program of upstream damming which threatens the flow of water downstream and the millions of people relying on it. Further, the explosion of rapids upstream to enable larger Chinese passenger and cargo boats to travel to northern Thai ports and the initiation of the carrying of oil on the river represents serious cross-border environmental problems. Cross-border issues generally have become more important in the era of globalisation and require international forums in which negotiations and debate might take place.

In terms of mainland Southeast Asia, the main forum for discussion is that of the Association of Southeast Asian Nations (ASEAN). Formed originally in the 1960s at a time when the Cold War fiercely divided the region, ASEAN was established as a means of international communication between neighbours who had little other means of multilateral communication and was organised strictly on the basis of mutual non-intervention, i.e., no state would be permitted to criticize or indeed even mention what another nation was doing within its own borders. This protocol has subsequently enabled Laos, Vietnam, Cambodia and Myanmar to have joined in recent years the five original members, Thailand, the Philippines, Singapore, Malaysia and Indonesia, together with Brunei, which joined thereafter. China has become both a leading external dialogue partner with ASEAN and, with South Korea and Japan, part of the ASEAN+3 Framework. ASEAN plus One (i.e. China) co-operation involves security co-operation, economic, trade and investment issues, science and technology, cross-border crime issues, ICT, youth, gender, health, law and customs issues. These are necessary to deal with problems such as the spread of disease (e.g. SARS, avian influenza, HIV/AIDS), human trafficking, organised crime, narcotics smuggling and other cross-border issues afflicting the region. ASEAN +3 also includes a number of additional issues, including poverty eradication and rural development, labour management, information, natural disaster management and others. In this case, ASEAN +3 is more concerned with ways in which the Three states can protect their investments in the Ten, although not everyone concerned would view the issue in such cynical terms.

Since Yunnan is frequently the geographical space in which these agreements are manifested, the infrastructure which is necessary to ensure these are enacted is built or created within or across its borders. This includes the building of roads and railways to increase connectivity within Yunnan and its neighbours, the establishment of customs and border trading posts and other physical representations. In addition to ASEAN, the Asian Development Bank (ADB) provides an almost wholly economic framework for uniting China and mainland Southeast Asia. One of the principal activities of the ADB with respect to Yunnan is the support of transportation infrastructure linking remote parts of the province with the remainder of the country and with mainland Southeast Asia, enabling them to take better advantage of existing and future economic opportunities. Examples of this include the Kunming-Haiphong Transport Corridor and No Bai-Lao Cai Highway Project, together with the Southern Yunnan Road Project and others. These projects not only aim to build tangible means of promoting development but also to bring in additional external funding partners as well as promoting confidence among partners and their technical capacity to increase cooperation through their own resources. As He Shengda (2006) observes, the Chinese state and provincial level governments have numerous opportunities to improve the ability of economic actors within Yunnan to increase co-operation, including the establishment of better cross-border legal and transportation regimes, promotion of Yunnanese commodity trades, strengthening tourism promotion, encouraging science and technology cooperation and similar measures. Governments on all sides have been quite good at talking up the possibilities of international co-operation but not always so good at finding ways of solving seemingly small but often intractable practical difficulties. Previous examples concerning the failure of the Singapore-Riau-Johor and Tumen River Growth Projects indicate the extent to which lack of trust and political will can undermine otherwise realizable and mutually beneficial agreements. 


\section{Outstanding Issues}

Some Thai enterprises in Yunnan in the past have failed and this has contributed to a certain reluctance to invest there again. Some respondents reported that the large state-owned enterprise Yunnan Textile Group Co. Ltd. (YTG) represents an unfair competitor, by virtue of its size and range of activities. YTG is not just a producer and distributor of household goods, including garments, toothpaste and cosmetics, but also manages its own wholesale and retail markets. Its Asian Building dominates the business environment. Thai businesspeople have so far been wary about entering into partnerships with YTG.

International business executives also struggle to come to grips with the guanxi or network connections aspect of doing business in Yunnan. Some respondents observed that many government procedures were opaque and poorly explained, as well as lacking in clear timeframes. One particular example of this concerns standards for hygiene. Respondents believed that good guanxi connections would help to abridge the time taken for the necessary procedures, although they observed that the law could not be sidestepped altogether. However, it is neither easy nor cheap to develop the guanxi, even if the executive recognises the need to do so. Most laws, for example, are written only in Chinese and very few qualified experts are available to interpret them into English or any other language. There is always a risk, therefore, of contravening the law in some way.

Thai respondents also complain about the $17 \%$ value added tax, although there are no specific tariffs on imported goods. However, the Chinese authorities have no intention of changing the tax, which affects every sale in the country, irrespective of its origin.

Most businesspeople in Kunming represent small or medium sized enterprises and they do their business in the traditional family style. Even if they are not genetically related or related by family ties, they will refer to each other as 'brother' to reflect a relationship of trust. When this has been established, the siblings will share information on customers and suppliers with each other. To reduce transaction costs, personal communications are preferred to official documentation. At one wholesale market, it is evident that dealers will make personal orders to their suppliers and the details are just recorded in a notebook. This system depends on trust among the participants and it is, of course, very difficult for outsiders to break in to such a system.

\section{Conclusion}

It became evident from the empirical research that the reality of doing business in Kunming and in Yunnan province generally is far from convenient. Many informal barriers exist and there is a lack of certain important resources that are required. This means that transaction costs are raised, especially for outsiders and, especially, for non-Chinese. Although it is not impossible for outsiders to develop trustworthy relationships and guanxi, this is difficult, expensive and time-consuming. Thai respondents present these facts as indicating bias or discrimination against foreign businesspeople but, in fact, similar situations exist with respect to international business in just about every country which is part of the capitalist world.

Cross-border economic activities and influence represent a form of soft power which may be used by states to improve the economic and social opportunities for their citizens and their other interests. This power unites China and mainland Southeast Asia, although currently the distribution of power appears to be asymmetric and this situation might intensify in the future. Will this power be used to affect such issues as labour laws in Thailand and the other countries involved? Or, given the lack of transparency in many government decisions in the region, perhaps it will be the case that those investors and business managers on the ground will receive the benefit of a blind eye in practice. However this is managed, it seems likely given past history that the economic imperative will be privileged above either the social or the environmental. Close scrutiny of what happens, therefore, will be of considerable importance.

Yunnan has spent some time emerging from its position as a lightly-developed border province to become a central part of one of the more dynamic regions of the world. As India continues to develop and enter into broader and deeper economic relationships with its neighbours, then Yunnan's position will continue to appreciate in importance. So long as Myanmar remains an intransigent military junta, no matter how well Chinese are able to manage relationships with them, then there will be a desire to route merchandise through Yunnanese territory. Border co-operation bureaucracy is improving with the mainland Southeast Asian states and, in due course, its extension to India will help further to increase the economic dynamism of the region.

For the entire province to flourish economically, though, more attention will need to be paid to soft skills as well as the hardware of infrastructure. Roads and buildings can be built quite easily but commercial success only comes through the ability of goods and service providers to offer trustworthy and transparent relationships and processes and policies. It is in these latter areas that particular attention will need to be paid, presumably at several levels of the educational system. 
In terms of the initial problem statement and research propositions, it may be observed that the private sector does seem to be playing an important part in propelling and shaping overall economic development in China, specifically in Yunnan province. The private sector is not essential to development in its early stages: after all, the CCP determined that resource extraction and the management of the agricultural sector would be the primary field of development and these activities were organised on the commodity basis of goods produced. As the economy has developed and become more complex, however, the private sector becomes more important (not necessarily more prevalent) in finding more value-added means of making profitable goods and services industries which would not be recognised in the purely public sphere. These factors seem to remain constant, irrespective of the cultural and social aspects of the superstructure that is supported by the economic base of the country.

\section{References}

Anantarangsi, S. and Walsh, J. (2009). Income distribution and mobility in Thailand: The perceptions of migrant workers in Bangkok and vicinity. NIDA Development Journal. 49:2. April-June. 51-78.

Arora, D. (2008). The Houses That Matsutake Built. Economic Botany. 62(3) (November). 278-90.

Atwill, D.G. (2003). Blinkered Visions: Islamic Identity, Hui Ethnicity, and the Panthay Rebellion in Southwest China, 1856-73. The Journal of Asian Studies 62(4). (November). 1079-1108.

Clements-Hunt, A. (2004). Cut Flowers: A Multi-Million Dollar Industry Blooms in Rural China. International Trade Forum. 4. 30-4.

Fullbrook, D. (2006). China Paves Way to Myanmar Riches. Asia Times Online. (November 1st). available at: http://www.atimes.com/atimes/Southeast_Asia/HK01Ae01.html.

Gan C. and Chen Z. (2004). Yunnan in Y.M. Yeung and Shen Jianfa, eds., Developing China's West: A Critical Path to Balanced National Development. Hong Kong: The Chinese University Press. 525-48.

Garnaut, R. and Song, L. (2004). Correcting Constraints to Private Enterprise Development: Lessons from a Private Sector Survey. in Garnaut and Song, eds., China's Third Economic Transformation: The Rise of the Private Economy. London and New York: RoutledgeCurzon. 225-35.

He, S. (2006). "Friendly and Wealthy Neighbors, Stable Nation:" Yunnan's Participation in the GMS, in Maria Serena I. Diokno and Nguyen Van Chinh, eds., The Mekong Arranged and Rearranged. Chiang Mai: SEASREP Foundation. 89-120.

List, D. (2004). Maximum Variation Sampling for Surveys and Consensus Group, Adelaide: Audience Dialogue. Available at www.audiencedialogue.org/maxvar.html.

Ma Y. and Li X. (1999). Yunnan. Kunming: Yunnan Institute of the Nationalities. Translated by He Changyi.

Phanishsham, A. (2006). Economic Implications of China's 'Go West' Policy: A View from Thailand. ASEAN Economic Bulletin. 23(2). 253-65.

Schliesinger, J. (2001). Tai Groups of Thailand: Vol.1: Introduction and Overview. Bangkok: White Lotus Co. Ltd.

Southiseng, N., Ty, M., Walsh, J., \& Anurit, P. (2008). Development of Excellent Entrepreneurs in Small and Medium Enterprises in Laos and Cambodia. GMSARN International Journal, 2(4), 147 - 156. Bangkok: AIT.

Southiseng, N. \& Walsh, J. (2008). Return and Informal Networks as Alternatives of Life Development. Proceedings of the Return Migration in Asia: Experiences, Ideologies, and Politics. National University of Singapore, $31^{\text {st }}$ July $-1^{\text {st }}$ August, 2008.

Suksamran, N. (2007). New Thai-Lao Bridge Throws up Old Problems. Bangkok Post (April 23 ${ }^{\text {rd }}$ ). Available at: http://www.bangkokpost.com/News/23Apr2007_news03.php.

Yang, H., Liu, C., Liu Y. and Duan Y. (2001). Man-chun-man Village at the Crossroads: Conservation and Vicissitudes of Ethnic Cultures during the Development of Tourism, in Tan Chee-Beng, Sidney C.H. Cheung and Yang Hui, Tourism, Anthropology and China. Bangkok: White Lotus Co. Ltd., 167-78.

Yunnan Copper May Acquire Copper Mine in Kazakhstan (2009). Metal Bulletin (July 12 ${ }^{\text {th }}$ ). 9127: 14.

Yunnan Government (2006), Yunnan Machinery Import \& Export Co. Ltd. Available online at: http://www.eng.yn.gov.cn/146648462866251776/index.html.

Zhang, X. (2005). China's 1979 War with Vietnam: A Reassessment. The China Quarterly. 184:851-874 